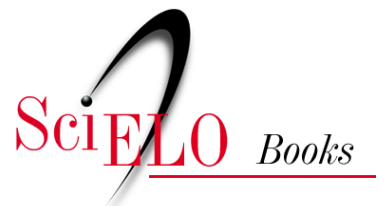

\title{
EDUFU
}

\section{Marx, Engels e a educação}

\author{
Carmen Sylvia Vidigal Moraes
}

\section{SciELO Books / SciELO Livros / SciELO Libros}

MORAES, C.S.V. Marx, Engels e a educação. In: BOTO, C., ed. Clássicos do pensamento pedagógico: olhares entrecruzados [online]. Uberlândia: EDUFU, 2019, pp. 89-113. História, Pensamento, Educação collection. Novas Investigações series, vol. 9. ISBN: 978-65-5824-027-3. Available from:

http://books.scielo.org/id/fjnhs/pdf/boto-9786558240273-06.pdf. https://doi.org/10.14393/edufu-978-85-7078-472-8.

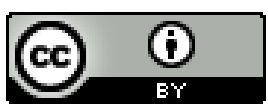

All the contents of this work, except where otherwise noted, is licensed under a Creative Commons Attribution 4.0 International license.

Todo o conteúdo deste trabalho, exceto quando houver ressalva, é publicado sob a licença Creative Commons Atribição 4.0.

Todo el contenido de esta obra, excepto donde se indique lo contrario, está bajo licencia de la licencia Creative Commons Reconocimento 4.0. 


\section{Marx, Engels e a educaçãa ${ }^{1}$}

Carmen Sylvia Vidigal Moraes

A teoria materialista de que os homens são produto das circunstâncias e da educação e de que, portanto, homens modificados são produto de circunstâncias diferentes e de educação modificada, esquece que as circunstâncias são modificadas precisamente pelos homens e que o próprio educador precisa ser educado. [...] A coincidência da modificação das circunstâncias e da atividade humana só pode ser apreendida e racionalmente compreendida como prática transformadora.

(Marx; Engels, 2007, p. 537-538)

$\mathrm{Na}$ obra de Marx e de Engels, a questão da educação e do ensino é tratada de maneira ocasional e fragmentária. No entanto, apesar de seus escritos não conterem estudos específicos sobre o tema, podem ser encontrados textos que tratam explicitamente de questões educacionais e problemas do ensino, cuja importância reside no fato de se apresentarem integrados à crítica radical das relações sociais

${ }^{1} \mathrm{O}$ artigo consiste em versão modificada e ampliada do texto apresentado no Simpósio Internacional realizado no centésimo aniversário da morte de Friedrich Engels, no Departamento de História da USP, em novembro de 1995, e publicado em Coggiola, O. (org.). Marx e Engels na História. São Paulo: Xamã, 1996. 
capitalistas e à necessidade de sua superação para a construção da nova sociedade e do novo homem. Tais análises apresentam-se de forma coerente em um intervalo de mais de trinta anos e coincidem com os momentos cruciais da investigação desenvolvida pelos autores e da história do movimento operário.

Além das considerações de Marx sobre as ações da Comuna de Paris no campo do ensino em 1871, a temática é desenvolvida em três programas políticos redigidos no período: para a criação do movimento que assumiu o nome de Partido Comunista, às vésperas da revolução de 1848; para as Conferências da I Associação Internacional dos Trabalhadores, entre 1866 e 1868; e para o Primeiro Partido Operário Unitário, na Alemanha, em 1875 (Manacorda, 1991; Palaciós, 1978).

Aos nossos objetivos, importa, com base nos pressupostos teóricos e metodológicos de Marx e Engels, como podemos apreender os processos educativos na realidade social. $\mathrm{O}$ relevante é que a análise marxiana da realidade social - inseparável, a meu ver, da contribuição de Engels - expressa uma visão determinada de homem e de sociedade e, portanto, apresenta uma concepção de educação.

Como nos propõe H. Lefebvre (1980, p.179-180), uma leitura enriquecedora da obra de Marx é a que a problematiza, que nos leva a apreendê-la como teoria crítica, ao mesmo tempo inacabada e portadora de um método de construção do conhecimento, o materialismo dialético, que é por pressuposto um materialismo histórico. Marx não explicitou o seu método por meio de uma exposição que pudesse facilitar a sua apreensão, ao contrário, o seu método foi se definindo ao longo da obra e "culmina na análise inacabada das classes sociais, isto é, sobre a primeira tríade - trabalho, terra e capital, ou seja, salário, preço e lucro" (Martins, 1996, p. 14). Dessa maneira, é preciso estudar em profundidade o seu pensamento para apreender os conceitos, a sua utilização e, sobretudo, o seu movimento.

No centro das preocupações de Marx está a questão da constituição da humanidade do homem, a relação entre o homem e a natureza. O núcleo explicativo do processo histórico é o homem 
que, por meio de sua atividade e para suprir suas necessidades, atua sobre a natureza e a modifica, modificando, ao mesmo tempo, as suas próprias condições de existência, constituindo-se como humano, humanizando-se.

Marx (1980 e 1987) sustenta que o trabalho é a essência do homem (da natureza histórica do homem). A partir da ideia de práxis, procura mostrar que o homem transforma o mundo por meio do seu trabalho e, ao transformar o mundo, transforma a si próprio. Nesta perspectiva, "a ligação entre educação e trabalho torna-se virtualmente muito forte" (Charlot, 2004, p.11).

\section{Algumas notas sobre questões de método}

Nos Manuscritos econômicos e filosóficos, de 1844, nos Grundrisse, assim como em $O$ capital, encontramos importantes indicações metodológicas. Seu método atinge proposições que concernem à globalidade social. Em toda a sua obra, Marx nos mostra que se não partirmos de uma concepção geral da sociedade, do conjunto, da globalidade do social, acabaremos chegando lá, exceto se pretendermos permanecer voluntariamente no nível do parcial, dos fatos e dos conceitos mal ligados teoricamente. A crítica da vida social implica, pois, mesmo quando refletimos sobre uma singularidade, concepções e apreciações que envolvem o conjunto do social. Não existem acontecimentos sociais ou homens sem ligação - conceitual, teórica, ideológica -, não existem grupos sociais que não estejam reunidos por relações num conjunto (Lefebvre, 1985; 1991).

Apreender a realidade social em sua globalidade significa apreender o acontecimento social em suas múltiplas relações, como totalidade em movimento, como unidade contraditória - pois a realidade possui não apenas múltiplos aspectos, mas também aspectos mutáveis e antagônicos. Os acontecimentos sociais são sempre apreendidos no seu devir, na sua historicidade. Não há determinismo histórico em Marx. Ao contrário, ele procura dar conta da diversidade temporal 
da realidade. A história - construída pelos sujeitos sociais a partir de limites sociais historicamente determinados - não é vista de forma linear e evolutiva. O tempo da história, para Marx, é imprevisto. A história é feita em cima do acaso. É claro que é socialmente determinada, mas não é uma história determinista - o que são coisas completamente diferentes.

Eu gostaria de me referir, também, a outro aspecto relevante: à existência ou não de um determinismo do econômico. Pode-se dizer que Marx nos mostra a substância de seu método em cada momento da análise das relações capitalistas de produção social. Nela não está presente qualquer forma de reducionismo do social ao econômico. Não foi Marx quem inventou a dominância do econômico na sociedade capitalista, mas é a prática social capitalista que elege o econômico como dominante. Para Marx, é impossível analisar qualquer dimensão da sociedade capitalista sem a mediação do econômico.

A esse respeito, é interessante citar a afirmação de Engels em carta a Joseph Bloch, datada de 21 de setembro de 1890 :

segundo a concepção materialista da história, o fator determinante da história é, em última instância, a produção e a reprodução da vida real. Nem Marx nem eu nunca afirmamos outra coisa. Se alguém em seguida torce essa proposição a ponto de dizer que o fator econômico é o único determinante, transforma-a numa frase vazia, abstrata, absurda. A situação econômica é a base, mas os diversos elementos da superestrutura [...] exercem igualmente sua ação sobre o curso das lutas históricas e, em muitos casos, determinam preponderantemente a sua forma. Existe uma interação entre todos esses fatores, no seio dos quais o movimento econômico acaba por abrir caminho, como uma necessidade através de uma multidão infinita de acasos². (Marx; Engels, 1961)

${ }^{2}$ A carta de Engels a Bloch encontra-se em Marx; Engels. Obras Escolhidas. Rio de Janeiro: Vitória, 1961, v. 2, p.284 
Para Marx, o ato econômico não pode ser reduzido à produção de coisas. É também produção de valor, de mais valia, do capital e do trabalho, ou seja, de relações sociais. Nessa acepção, é imediatamente produção e reprodução de relações de exploração e dominação, de relações de poder. $\mathrm{O}$ que o constitui, ao mesmo tempo e no mesmo movimento, em produção e reprodução de representações políticas, jurídicas, ideológicas, de valores, de normas e de justificativas capazes de permitir a reprodução dessas relações.

Constrói-se, nesse processo, o aparato ético e o jurídico - o Direito - com base nas relações de propriedade inerentes às relações de produção da sociedade capitalista; criam-se representações da igualdade entre os homens, da vigência da liberdade. Representações que se circunscrevem ao mercado, à circulação, encobrindo as desigualdades reais, as relações de exploração originárias no âmbito da produção. Por isso, para Marx, no modo capitalista de produção social, a produção das múltiplas dimensões da realidade ocorre em um mesmo ato: não é possível separar o econômico do político, do "cultural", do ideológico. E é ainda constitutivo de seu método a necessidade de superar as representações aparentes para se atingir o movimento real.

É assim que, nos Grundrisse, ao explicitar o conceito de modo de produção, Marx designa-o como resultado global das relaçóes de antagonismo salário/capital, proletariado/burguesia. Essas relações de antagonismo surgem na prática social por meio de formas que as sustentam e mascaram, por exemplo, a forma contratual (a do "contrato de trabalho", ficticiamente livre, que liga os membros da classe trabalhadora e os da burguesia, e que pretensamente os associa):

Marx chama a atenção para o fato de que a mercadoria adquire sua forma perfeita quando é avaliada em equivalente geral. Como forma, a mercadoria dissimula as relações entre os produtores e o caráter social dos trabalhos privados, ao invés de evidenciá-los. A forma se fetichiza como mercadoria, como dinheiro, criando aparências reais encobrindo o real e, ao mesmo tempo, dele fazendo parte. Fetichizada, 
adquire duas propriedades: se autonomiza como coisa (abstrata) e dissimula as relações sociais (Oliveira; Moraes, 1996, p.100).

Esse resultado global compreende, portanto, "as elaborações jurídicas das relações de produção, as relações de propriedade codificadas - as ideologias que 'exprimem' também, dissimulandoas, as relações de antagonismo - as instituições políticas e 'culturais', a ciência etc." (Lefebvre, 1973, p. 48). Dessa maneira, a coesão das relações sociais é realizada pela forma política. Nela se expressam os sentimentos (obrigações, sanções morais) da sociedade como um todo colocados pelo Estado. O Estado reúne a eficácia prática e política da forma (Oliveira e Moraes, 1996, p. 104).

Ou seja, mecanismos como a alienação e a reificação, conectados ao "fetichismo da mercadoria", são necessários socialmente; a sociedade burguesa não pode existir sem eles, que acabam por criar uma aparência coisificada da realidade social. Os fenômenos sociais aparecem "sob a forma de coisas, alheias aos homens e às suas relações" (Netto, J.P; Braz, M., 2007, p. 92).

Não há, assim, história sem tensões, sem contradições. No plano do vivido (Lefebvre, 1973, p.14), a práxis é contraditória. Ela reproduz relações sociais. No "Capítulo Inédito de O Capital" (1984, p. 94-95), Marx observa que "há produção de relações sociais no seio da reprodução", isto é, não há reprodução sem produção de novas relações, não há repetição sem certa inovação ${ }^{3}$.

Em Marx, práxis e estrutura não são jamais separadas. Não é casual ele afirmar, nos Gundrisse (1987), que o capitalismo é não tanto uma estrutura quanto um processo. De fato, Marx vê a estrutura capitalista em sua historicidade, como devir, como movimento inacabado, de acordo com seu método genético estrutural

\footnotetext{
${ }^{3}$ A obra de Marx e Engels resulta de um contexto político determinado, presente no século XIX. Como afirma J. P. Netto (1985, p. 22), "é uma resposta aos problemas colocados pela sociedade burguesa e uma proposta de intervenção que tem como centro a classe operária”.
} 
- progressivo regressivo, segundo Lefebvre (1971, p.168) - que lhe é próprio. $\mathrm{O}$ método de Marx parte de noções estruturais, de categorias estruturais fundamentais, e dessas determinações abstratas eleva-se posteriormente até o concreto, até a complexidade e a multiplicidade globais do concreto. Não é a história em função da estrutura, mas, sim, a estrutura em função da história ${ }^{4}$.

Ao contrário do historicismo alemão, Marx vê na concreticidade histórica as permanências, os elementos que se repetem - leis, estruturas - e as mudanças, que nos permitem compreender os elementos que compõem o evento histórico singular, ou seja, temos a possibilidade de uma fundamentação científica da historiografia, da sociologia, do estudo da sociedade e do seu devir. Nesse sentido, o marxismo escapa do perigo do relativismo. E o que é fundamental: quando Marx estuda, de modo crítico, a economia política e utiliza metodicamente os conceitos, é para mostrar cientificamente a possibilidade da subversão, de sua superação, da revolução. Ele quer indicar que existe "uma unidade entre a linguagem e a vida social ordinária, aquela do conhecimento, aquela da atividade revolucionária”. Entre teoria e prática, segundo Marx, "há unidade, não somente lógica, mas dialética: diferença, frequentemente conflito, mas na unidade" (Lefebvre, 1971, p.166).

\section{Sobre educação e ensino}

No que se refere à problemática educacional, as formulações de Marx e Engels têm dado origem a dois tipos predominantes de abordagem: as que estudam, no conjunto da obra, os conteúdos e significados dos enunciados relativos à sua visão educacional, e as que, fazendo uso de suas categorias de análise, realizam a crítica das concepções liberais de educação, da escola capitalista.

Com base nos textos de Marx e Engels e na contribuição de

${ }^{4}$ A esse respeito, consultar Lefebvre (1973) e Martins (1996, p. 9-13). 
alguns estudos e pesquisas concernentes à temática ${ }^{5}$, pretendo centrar a exposição no relato histórico da contribuição de Marx e Engels ao estudo da relação trabalho e educação, e - ainda que de forma sintética - examinar os seus fundamentos filosóficos e econômico-políticos.

É possível afirmar, numa primeira aproximação conceitual, que Marx e Engels concebem educação como "processo social geral (a sociedade como sendo, toda ela, um ambiente educativo), analiticamente apreendido como dimensão dos demais processos sociais inclusivos [...] - isto é, a educação como processo socializador" (Pereira, 1965, p. 53). Toda relação social é uma relação pedagógica. As práticas escolarizadas consistem em apenas uma dimensão do processo educacional, o qual perpassa o conjunto da sociedade e se dá por meio das diferentes instituições sociais. Contrariamente à visão liberal da “comunidade de interesses”, trata-se de uma sociedade constituída por grupos e classes sociais que se situam diferentemente face às relações de produção social e são portadores de interesses opostos e antagônicos. Os interesses socialmente dominantes são os das classes dominantes.

\section{A questão da relação educação e trabalho}

\section{A união entre ensino e trabalho}

Embora haja mudanças nas propostas educacionais de Marx e Engels apresentadas no Manifesto comunista, em 1848, e nas Críticas ao Programa de Ghota, em 1875, passando pela Ideologia alemã e O capital, o que persiste é a ideia da necessidade, para os trabalhadores, da união do ensino com o trabalho.

Em os Princípios do comunismo, primeira versão redigida por Engels, em 1847, do que viria a ser o Manifesto do Partido Comunista na redação definitiva de Marx em 1848, já se defende, como uma das medidas imediatas mais importantes destinadas a assegurar existência

\footnotetext{
${ }^{5}$ Entre outras contribuições, estão os trabalhos de Dangeville (1976), Palaciós (1978), Nogueira (1990), Machado (1989), Gramsci (2000), Manacorda (1991) e Charlot (2004), entre outros.
} 
digna ao proletariado e a preparar os trabalhadores para a luta contra a propriedade privada dos meios de produção, "a instrução a todas as crianças, assim que possam prescindir dos cuidados maternos, em institutos nacionais e às expensas da nação. Instrução e trabalho de fábrica vinculados". O Manifesto do Partido Comunista, escrito nos dois meses seguintes, reafirma a proposição. Além de defender a "educação pública e gratuita para todas as crianças" e a abolição do trabalho infantil nas fábricas, propõe "a integração da educação com a produção material” (Marx; Engels, 1998, p. 28).

Em Instrução sobre diversos problemas aos delegados do Conselho Central Provisório, escrito por Marx em 1866, como programa a ser apresentado no Primeiro Congresso da Internacional Comunista, assim como em Critica ao Programa de Gotha, ou em outras passagens da obra de Marx e Engels, repete-se a defesa desse mesmo princípio da união do ensino com o trabalho produtivo.

A tese da combinação ensino-trabalho, como tem sido salientada por alguns estudiosos, não foi criada por Marx e Engels, mas já havia aparecido no pensamento pedagógico, enunciada, sobretudo, pelos socialistas utópicos do século XIX e, em particular, pelo francês Charles Fourier (1772-1837) e pelo inglês Robert Owen (1771-1858). Esse último, coproprietário de uma fábrica têxtil em New Lanark, na Escócia, colocará em prática seus ideais filantrópicos, instaurando em suas empresas princípios cooperativos de gestão, e organizando, nas colônias que fundara, um sistema de escolas destinadas a implementar suas ideias educacionais baseadas no valor educativo do trabalho manual (Nogueira, 1990, p. 100-105).

No livro primeiro de $O$ capital, Marx refere-se, mais de uma vez, às experiências de Robert Owen, demarcando sua importância:

Quando Robert Owen, logo depois do primeiro decênio deste século, não só defendeu teoricamente a necessidade de uma limitação da jornada de trabalho, mas também introduziu realmente a jornada de 10 horas em sua fábrica de New Lanark, isso foi ridicularizado como 
utopia comunista, assim como a sua 'união de trabalho produtivo com educação de crianças', assim como as empresas cooperativas de trabalhadores fundadas por ele. Hoje em dia, a primeira utopia é a Lei Fabril, a segunda figura como frase oficial em todas as Factory Acts e a terceira já serve até como manto de cobertura para embustes reacionários (Marx, 1984, p. 361).

No entanto, embora o socialismo utópico tenha inspirado o pensamento de Marx e Engels, é preciso salientar que eles não se limitaram a recolher tais propostas, mas aprofundaram-nas e superaram-nas. Conforme consideram Nogueira (1990) e Dangenville (1978), o exame das novas condições sociais criadas pela Revolução Industrial Inglesa, com a introdução do maquinismo e sua divisão técnica do trabalho, assim como o emprego generalizado da mão de obra infantil, foi determinante para o desenvolvimento da formulação educacional dos autores.

Preocupado com a exploração do trabalho das crianças, Marx escreve:

Do sistema fabril,que podemos acompanharem detalhes lendo a Robert Owen, brota a semente da educação do futuro, na qual se combinarão para todas as crianças, a partir de certa idade, o trabalho produtivo com o ensino e a ginástica, não só como método para intensificar a produção social senão também como o único método que permite produzir homens plenamente desenvolvidos (Marx, 1984, p.589).

A "dilapidação desenfreada" da força de trabalho, na expressão de Marx, levou o Parlamento inglês a forjar dispositivos legais com o objetivo de limitar os excessos cometidos pelos fabricantes. Ao longo do século XIX, foram produzidos inúmeros textos que regulamentavam, sobretudo, as condições de admissão das crianças e adolescentes nas fábricas e a duração da jornada de trabalho. A lei de 1833, por exemplo, condicionava a admissão da criança nas empresas ao controle de uma 
frequência escolar diária de pelo menos duas horas. Para Marx (1984, p. 588), isso significava "antes de tudo, a possibilidade de conjugar ensino e ginástica com trabalho manual".

Assim, Marx e Engels fundaram seus princípios educativos nas conquistas obtidas pelos trabalhadores no confronto com os capitalistas, expressas nas leis fabris, na perspectiva de fazê-las avançar:

Se a legislação fabril, essa primeira concessão penosamente arrancada ao capital, não vai mais além de combinar o ensino elementar com o trabalho nas fábricas, não há dúvida alguma de que a conquista inevitável do poder político pela classe operária também conquistará o devido lugar para o ensino tecnológico - teórico e prático - nas escolas operárias (Marx, 1984, p. 589).

$\mathrm{Na}$ Critica ao Programa de Gotha, levando em conta a conjuntura política, Marx afirma a importância estratégica da educação, tanto para coibir os abusos da exploração de crianças como para viabilizar a elas uma formação geral, técnica e política:

A proibição geral do trabalho infantil é incompatível com a existência da grande indústria e, portanto, não passa de um desejo piedoso, nada mais. Colocar em prática essa proibição, supondo-se que fosse possível, seria reacionário, já que, regulamentada severamente a jornada de trabalho segundo as distintas idades e aplicadas as demais medidas preventivas para a proteção das crianças, a combinação em boa hora do trabalho produtivo com o ensino é um dos mais poderosos meios de transformação da sociedade atual (Marx; Engels, 1972, p. 49).

Nas Instruções aos delegados do primeiro Congresso da Associação Internacional dos Trabalhadores - $\mathrm{AIT}^{6}$, realizado em

${ }^{6}$ Sobre as atas dos Congressos da AIT, ver também Nogueira (1990) e Dangeville, 1976; 1978. 
Genebra no ano de $1866^{7}$, Marx declara:

A sociedade não pode permitir nem aos pais, nem aos patrões, o emprego de crianças e adolescentes para o trabalho, a menos que combinassem este trabalho produtivo com a educação. Por educação nós entendemos três coisas: I) a educação mental; 2) a educação corporal, tal qual é produzida pelos exercícios ginásticos e militares;3) a educação tecnológica, compreendendo os princípios gerais e científicos de todos os processos de produção e, ao mesmo tempo, iniciando as crianças e os adolescentes no manejo dos instrumentos elementares de todos os ramos industriais.

\section{E complementa:}

À divisão das crianças e adolescentes em três categorias, de 9 a 18 anos, deve corresponder uma marcha gradual e progressiva em sua educação mental, física e tecnológica. Os gastos dessas escolas técnicas devem ser cobertos, em parte, pela venda de seus produtos. Essa combinação do trabalho produtivo pago com a educação mental, os exercícios corporais e a aprendizagem politécnica elevará a classe operária bem acima do nível das classes burguesa e aristocrática. Fica subtendido que o emprego da criança ou adolescente, entre 9 e 18 anos, em qualquer tipo de trabalho noturno ou em qualquer ramo de trabalho industrial que possa acarretar efeitos nocivos para a saúde, deve ser severamente punido.

7 A criação da AIT, em Londres, em 28 de setembro de 1864, pode ser interpretada como "uma resposta operária à universalização do sistema capitalista" (Tragtenberg, 1986, p. 19). Ao "agregar trabalhadores de diversos países da Europa, vinculada a organizações como a Associação para a Educação de Trabalhadores, de Londres, chefes da Trade-Unions, adeptos de Garibaldi, de Blanqui, de Marx e de Proudhon, a associação "logrou-se a transformarse na representante da quase totalidade das organizações independentes do movimento trabalhista na Europa e a levá-las todas a se darem as mãos numa ampla cooperação e a discutirem seus objetivos e estratégias" (Santos, 2014, p. 36; Abendroth, 1977, p. 37). 
Importava a Marx e Engels, antes de mais nada, defender a força de trabalho infantil da voracidade dos fabricantes, bem como dos abusos cometidos pelos próprios pais e, naquele momento, isso só parecia ser possível por meio da pressão social capaz de arrancar do Estado leis de proteção à infância operária (Nogueira, 1990). Nesse sentido, ele apresenta algumas recomendações de ordem prática, contrapondo-se, no tocante à limitação da jornada de trabalho infantil, às estipulações da lei de fábrica inglesa de 1833. Assim, como se viu, contrapondo-se às 9 horas de trabalho para as crianças de 9 a 13 anos, e às 12 horas para as de 14 a 18 anos, Marx propõe, de acordo com sua divisão em três faixas etárias, 2 horas diárias para as crianças de 9 a 12 anos, 4 horas para as de 13 a 15 anos e 6 horas para as de 15 a 18 anos.

A ideia de prescrever 9 anos como idade de entrada no trabalho e na escola está relacionada à mesma lei de 1833, que autorizava o trabalho infantil a partir dessa idade (Palaciós, 1978; Nogueira, 1990).

De acordo com Marx, em Instruções aos delegados do Conselho Geral Provisório:

Seria desejável que as escolas elementares começassem a instrução das crianças antes da idade de nove anos. Mas, no momento, só devemos pensar nas medidas absolutamente necessárias para contra-arrestar as tendências de um sistema social que degrada o operário, a ponto de torná-lo um mero instrumento para a acumulação do capital, e que, fatalmente, transforma os pais em mercadores de escravos que vendem os seus próprios filhos. $\mathrm{O}$ direito das crianças e dos adultos deve ser defendido, uma vez que eles não podem fazê-lo por si mesmos. É, portanto, dever da sociedade agir em seu nome.

Anos mais tarde, em 1875, dirigindo-se ao Partido Social-Democrata alemão, Marx reafirma sua preocupação com o desenvolvimento físico e mental da criança operária e com a regulamentação de suas condições de trabalho, declarando: 
desde que se garanta uma rigorosa regulamentação do tempo de trabalho segundo as faixas etárias, bem como outras medidas de proteção das crianças, o fato de combinar, desde tenra idade, o trabalho produtivo com a instrução constitui-se num dos mais poderosos meios de transformação da sociedade atual (Marx; Engels, 1972, p. 49).

A insistência de Marx e Engels na necessidade da união do trabalho com a instrução, de superar a cisão entre o trabalho intelectual e o trabalho manual, deve ser entendida no interior de sua crítica geral à divisão do trabalho existente na sociedade capitalista.

Retomando algumas noções fundamentais na obra de Marx, vimos que o trabalho consiste em noção fundamental. Por meio do trabalho, o homem se separa da natureza e se faz homem, ser social. O trabalho é, ontologicamente, a força propulsora da humanização do homem, da constituição do ser social. No entanto, na sociedade capitalista, o trabalho se realiza historicamente como alienação.

Em determinadas condições histórico-sociais, os produtos do trabalho e da imaginação humana deixam de se mostrar como objetivações que expressam a humanidade dos homens; aparecem como algo que, escapando ao seu controle, passa a controlá-los como um poder que lhes é superior. Em suma, entre os homens e o produto de seu trabalho, a relação real, que é a relação entre criador e criatura, aparece invertida - a criatura passa a dominar o criador. Essa inversão caracteriza o fenômeno histórico da alienação (Netto; Braz, 2007, p.34 e 44). Basicamente, a alienação é própria das sociedades em que tem vigência a divisão do trabalho e a propriedade privada dos meios de produção fundamentais, sociedades nas quais o produto da atividade do trabalhador não the pertence, nas quais o trabalhador é também expropriado dos meios de produção, do domínio do processo de trabalho, tornando-se estrangeiro a si próprio, "alienado".

O fruto da divisão social e técnica do trabalho é o homem unilateral, fragmentado e encerrado na clausura do trabalho dividido. Para Marx e Engels, a educação constitui dimensão importante da 
luta de classes rumo à reintegração do trabalhador fragmentado e à superação da alienação.

É importante enfatizar o significado central que Marx confere ao trabalho na sua dimensão concreta, como criador de valores úteis, em contraposição à coisificação que caracteriza o trabalho assalariado, criador de valores de troca (Antunes, 1996, p.98).

O Marx dos Manuscritos econômicos e filosóficos de 1844 e dos Gundrisses sustentará que o trabalho, como valor de uso, é a essência do homem. Com base na ideia de práxis, o homem transforma o mundo, e ao transformar o mundo por meio de seu trabalho, ele transforma a si próprio, ele se forma. Como nos indica B. Charlot (2004, p. 11-12),

a concepção de Marx de que o trabalho forma, e de que só ele pode formar, incluindo no plano moral e social, está tão profundamente arraigada no mundo operário que Proudhon e os socialistas do século XIX negaram com força a ideia de escola gratuita e obrigatória. Para os trabalhadores, tratava-se de uma armadilha da burguesia que queria impedir que os seus filhos fossem educados no atelier onde aprendiam a solidariedade de classe. Quanto a Marx, ele considerava que cabe ao povo educar o Estado, e não ao Estado educar o povo.

De modo geral, os textos escritos para os Congressos da AIT (1866, 1868 e 1869) oferecem indicações claras sobre as concepções de Marx sobre educação e suas propostas relacionadas à organização do ensino.

Em 1867, no Congresso de Lausanne, foi formada uma comissão para estudar os seguintes temas: "funções sociais; papel do homem e da mulher na sociedade; educação das crianças; ensino integral; liberdade de ensino; fonografia" (Freymond, 1962, p. 98). $\mathrm{O}$ relatório produzido pela comissão propunha que o ensino fosse obrigatório, gratuito e dispensado pelo Estado. No entanto, os debates desenvolvidos na Primeira Internacional mostram que os primeiros congressos não formularam resoluções comuns em relação à gestão 
escolar, por causa da hostilidade de boa parte de seus membros em relação às propostas de um ensino público.

Em 1869, de acordo com as atas do Congresso da AIT em Basileia Marx afirmava ${ }^{8}$ existir uma "dificuldade de ordem particular" ligada à questão da educação na sociedade moderna:

De um lado, é preciso haver mudanças nas condições sociais para criar um sistema de instrução novo; de outro lado, é preciso um sistema de instrução já novo para poder mudar as condições sociais. Em consequência, é preciso partir da situação atual.

A respeito da questão do ensino público, gratuito e obrigatório, a ata da sessão do Congresso de Basileia, no dia 10 de agosto de 1869, transcreve a posição de Marx sobre o tema:

O ensino pode ser estatal sem que se encontre sob o controle do governo. O governo poderia nomear inspetores cujas atribuições seriam zelar para que a lei seja respeitada, sem que eles tenham o direito de se imiscuir diretamente no ensino. Seria como para os inspetores de fábrica que zelam pelo respeito das leis de fábrica. O Congresso pode decidir sem a menor obrigação que o ensino deve ser obrigatório. No que tange ao fato de que as crianças deveriam ser obrigadas a trabalhar, o que é certo é que isso não ocasionaria uma baixa dos salários, e todo o mundo se habituaria a isso. Os proudhonianos afirmam que o ensino gratuito é um contrassenso, pois que o Estado deve pagar. É evidente que alguém deve pagar, mas que não sejam aqueles que menos têm condições de fazê-lo.

${ }^{8}$ Os escritos e pronunciamentos de Marx nas Conferências da Primeira Internacional são encontrados em Instruções para os delegados do Conselho Geral Provisório a propósito de diversas questóes (extrato), reproduzido por Dangeville, R. (1976 e 1978), e em La Première Internationale .J. Freymond (org.). Genève: Droz, 1962, 2 v. Sobre as atas dos Congressos da AIT, ver também Nogueira, M. A. (1990), Musto (2014), Marx e Engels (1976 e 1978 - org. Dangeville). 
Marx parece compartilhar com os proudhonianos a desconfiança em relação à tutela governamental sobre o ensino, posição que expressa claramente na sua crítica ao Programa de Gotha, em 1875:

Uma “educação do povo pelo Estado" é algo absolutamente condenável. Determinar através de uma lei geral os recursos para as escolas primárias, os atributos exigidos do pessoal docente, as disciplinas ensinadas etc. e, como ocorre nos Estados Unidos, fiscalizar, com a ajuda de inspetores do Estado, a execução dessas prescrições legais, é absolutamente diferente do que fazer do Estado o educador do povo! Mais do que isso, é preciso banir da escola, do mesmo modo, toda a influência do governo e da Igreja. E, mais ainda, no Império prussoalemão (e que não se venha com essa escapatória falaciosa de falar em um certo "Estado do futuro": já sabemos do que se trata); é, ao contrário, o Estado que precisa ser educado de uma maneira rude pelo povo" (Marx; Engels, 1972, p. 47).

Sem querer debater aqui a concepção marxiana de Estado, é importante lembrar - como o faz Maria Alice Nogueira (1990, p. 195) - uma passagem de Henri Lefebvre (1974, p.110) na qual o autor afirma que "o pensamento marxista é fundamentalmente antiestatal" e que a ideia de um socialismo de Estado - segundo a qual o Estado é gestor da economia e princípio superior da sociedade - não deriva de Marx, mas de um homem cujas posições ele combatia: Ferdinand Lassale.

Nessa direção, no prefácio para a edição de $A$ guerra civil na França, de K. Marx, publicada em Berlim em 1891, F. Engels escreve:

Em realidade, o Estado não é mais que uma máquina para a opressão de uma classe por outra, tanto na República democrática como sob a monarquia; e, no melhor dos casos, um mal que se transmite hereditariamente ao proletariado triunfante em sua luta pela dominação de classe. Como fez a Comuna, o proletariado vitorioso 
não pode deixar de amputar imediatamente, na medida do possível, os aspectos mais nocivos desse mal, até que uma futura geração, formada em circunstâncias sociais novas e livres, possa desfazer-se de todo esse velho traste do Estado. Ultimamente, as palavras 'ditadura do proletariado' voltaram a despertar sagrado terror ao filisteu social-democrata. Pois bem, senhores, quereis saber que face tem essa ditadura? Olhai para a Comuna de Paris: eis aí a ditadura do proletariado! (Marx, 2011, p. 197)

Se, quanto ao ensino público, há certa oscilação no pensamento de Marx, no que se refere à gratuidade do ensino, à obrigatoriedade escolar e ao laicismo não há qualquer ambiguidade, tratando-se para ele "de princípios indiscutíveis" (Nogueira, 1990, p. 198), tal como o vimos se manifestar nas discussões do Congresso de Basileia.

Em seu livro A guerra civil na França, Marx analisa as medidas tomadas nessa direção pela Comuna de Paris em 1871. No que concerne à gratuidade, afirma que ela deveria se estender até mesmo ao material escolar, como havia previsto a Comuna, reivindicando o que chamamos hoje de gratuidade ativa:

A Comuna não teve naturalmente tempo para reorganizar a instrução (educação) pública. Contudo, ao eliminar o elemento religioso e clerical, tomou a iniciativa de emancipar intelectualmente o povo. A 28 de abril, nomeou uma comissão encarregada de organizar o ensino primário (elementar) e profissional. Ordenou que todos os instrumentos de trabalho escolar, tais como livros, mapas, papel, etc. fossem fornecidos gratuitamente pelos professores que, por sua vez, deveriam recebê-los das respectivas circunscrições administrativas a que pertencem. Nenhum professor está autorizado, sob pretexto algum, a cobrar de seus alunos pelos instrumentos de trabalho escolar (Marx, 2011, p. 117).

No que concerne especificamente à educação politécnica, é 
também a ata do Congresso de Basileia, de 1869, que nos apresenta a percepção de Marx sobre a discussão dos trabalhadores da AIT sobre a proposta:

O cidadão Marx diz que todos estão de acordo sobre certos pontos determinados. A discussão ocorreu após ter sido proposto ratificar a resolução do congresso de Genève, que reivindica combinar o ensino intelectual com o trabalho físico, os exercícios de ginástica à formação politécnica. Ninguém tem feito objeção a este projeto. A formação politécnica, que foi sustentada por escritores proletários, deve compensar os inconvenientes resultantes da divisão do trabalho que impedem os aprendizes de assimilar um conhecimento aprofundado de seu ofício. Sobre este ponto, sempre se partiu do que a própria burguesia entende sobre educação politécnica, e foi isto que provocou interpretações errôneas.

Sobre esse aspecto, no manuscrito anexo a Trabalho assalariado e capital (1849), intitulado O salário, Marx considera:

Uma outra reforma muito apreciada pelos burgueses é a educação, particularmente a educação profissional universal. Não pretendemos realçar a absurda contradição segundo a qual a indústria moderna substitui cada vez mais o trabalho complexo pelo trabalho simples para o qual não há necessidade de qualquer formação; também não queremos realçar que ela empurrou cada vez mais crianças a partir dos sete anos para detrás das máquinas, fazendo delas uma fonte de lucros tanto para a classe burguesa como para seus próprios pais proletários. O sistema manufatureiro põe em causa a legislação escolar - como é disso testemunha a Prússia. (Marx, 1976, p. 71-72)

Em seguida, enfatiza:

(...) queremos finalmente realçar que a formação intelectual, se o 
operário a tivesse, não exerceria influência direta sobre o seu salário; que a instrução geral depende do nível das condições de vida, e que o burguês entende por educação moral o enfarto de princípios burgueses; e que afinal de contas a classe burguesa não possui os meios nem o desejo de oferecer ao povo uma educação verdadeira. (Marx, 1976, p. 71-72, grifos meus).

O conceito abstrato de trabalho, o trabalho como valor de troca, é “essencial à compreensão do movimento histórico" que constitui o desenvolvimento do capitalismo e do assalariado (Schwartz apud Charlot, 2004, p.17).

Marx e Engels insistem, como vimos, na necessidade de suprimir a divisão do trabalho, rompendo com os obstáculos ao desenvolvimento integral humano. Ao falarem da supressão da divisão do trabalho, referem-se tanto à divisão social do trabalho como à sua divisão técnica, fruto específico do capitalismo industrial, que subdivide o trabalhador e introduz, pela primeira vez na história, a separação entre concepção e execução do trabalho. É aqui que, para Marx, a combinação dos estudos teóricos (concernentes principalmente à tecnologia da produção) com a prática do trabalho na fábrica constituiria instrumento fundamental para acirrar as contradições sociais e promover a superação da divisão do trabalho. É nesse sentido que, como se viu, Marx encoraja a AIT a incluir em sua plataforma a reinvindicação por uma formação politécnica para os trabalhadores.

\section{A proposta da educação integral}

Os historiadores da educação e do trabalho têm centrado suas análises da posição de Marx e dos trabalhadores da Primeira Internacional na questão do ensino politécnico e em sua relevância estratégica para o rompimento da divisão e fragmentação do trabalho.

Entretanto, a proposta da educação integral, pouco mencionada nos estudos sobre os debates e resoluções dos Congressos da AIT, mostra que o questionamento das atribuições sociais da escola sob o 
capital é realizado no âmbito da problematização das relações entre educação e trabalho.

Assumindo perspectiva crítica, capaz de complementar e tornar mais clara a concepção de ensino politécnico, a proposta de educação integral, ligada à história do movimento revolucionário do século XIX, colocava-se contrária à existência de dois tipos de instrução - uma "aprimorada", reservada aos burgueses, e outra "simplificada", destinada aos trabalhadores, expressão da dominação de classe - e em defesa de uma educação igualitária que possibilitasse "o pleno desenvolvimento de todas as capacidades do indivíduo", "integrando o trabalho manual e o intelectual"'.

Tal concepção emancipatória de educação, a da construção de uma escola unitária que integrasse formação geral e formação profissional, propunha superar os métodos e a organização da escola reprodutora das desigualdades sociais, considerando essencial que o ensino partisse das relações concretas da vida e o trabalho fosse compreendido de forma criativa, artística e integral. Tais concepções pedagógicas presentes no "Programa de Ensino Integral", elaborado pelo educador Paul Robin e apresentado nos Congressos da Internacional de Trabalhadores em Lausanne (1867) e em Bruxelas (1868), foram aprovadas consensualmente pelos seus participantes $^{10}$.

Apesar dos conflitos entre as diferentes correntes políticas, a concepção de educação integral e igualitária foi assumida como exigência prioritária pela Primeira Internacional por Bakunin, Proudhon e

\footnotetext{
${ }^{9}$ A crítica à dualidade da escola capitalista e a proposta de educação integral estão também presentes, entre outros temas, nas formulações de Bakunin e, mais tarde, nas de Francisco Ferrer, criador da Escola Moderna de Barcelona. A esse respeito, consultar Bakunin (2003) e Ferrer y Guardia (1970).

${ }^{10} \mathrm{O}$ Programa de Ensino Integral, elaborado por Paul Robin e apresentado nos Congressos da Internacional de Trabalhadores em Lausanne (1867) e em Bruxelas (1868), foi, posteriormente, incorporado ao "Programa Educacional do Comitê para o Ensino Anarquista", de 1882, após o encerramento da Internacional (1876). A esse respeito, ver também Luizetto (1986, 1987), Moraes et al. (2011) e Santos (2014).
} 
Marx, e pelas tendências que representavam (Luizetto, 1986; Moraes et al., 2011).

Pode-se afirmar que, nessa perspectiva educacional, a concepção do trabalho como princípio educativo, aprofundada mais tarde por Antonio Gramsci ${ }^{11}$, apreende o trabalho não só como conceito abstrato, mas também como experiência concreta, como valor de troca e como valor de uso, ou seja, não apenas como momento de exploração e de dominação, mas também "como momento de formação e de partilha de uma atividade", "forma de atividade humana" (Charlot, 2004, p. 18), como possibilidade de criação e realização do homem que o exerce na perspectiva da superação do alheamento e da exploração.

Nesse registro, o trabalho - centro da vida social - aparece, no plano subjetivo, "como pleno desenvolvimento da atividade (pessoal)", como desenvolvimento da individualidade ou como "produção de si"; e, no plano coletivo, como "produção da sociedade", ou "produção social da vida", "produção da política" (Pfefferkorn, 2007; Lukacs, 2004; Clot, 1995).

A proposta de educação integral que visa ao desenvolvimento integral do trabalhador, referendada por Marx ao apreender o trabalho em sua dupla acepção, atribui-lhe sentido mais largo do que o de "trabalho profissional" e permite apreender a escola não só como espaço de reprodução, mas também como produtora de relações novas, inscrevendo a educação em abordagem mais ampla, como atividade bumana, como "trabalho" de produção de si, visão que a lógica predominante da educação como valor de troca, como mercadoria, obscurece (Charlot, 2004, p. 16).

\section{Considerações finais}

Historicamente, o modelo de educação que predominou é o da "educação pela escola" e não o da "educação para o trabalho e pelo trabalho". Como considera B. Charlot (2004, p. 12; 13), "trabalho e

${ }^{11}$ Consultar, a esse respeito, Gramsci (2000, p. 15-53). 
educação serão desligados na organização da escola do povo”, e embora essa escola possua "um discurso positivo sobre o trabalho", o "trabalho é ignorado como realidade".

Hoje, retomando a questão central da constituição da humanidade do homem diante das atuais mudanças tecnológicas e organizacionais do trabalho, do "moderno" conceito de produção, momento em que cada vez mais a escola é vista "como acesso ao mercado de trabalho", em que a lógica predominante reduz a educação a valor de troca, isto é, quando "a educação não é um trabalho e o trabalho não é pensado como educação” (Charlot, 2004, p.16), quais desafios nos colocam as proposições de Marx e Engels?

$\mathrm{Na}$ atual conjuntura de intensa disputa na política educacional brasileira, em particular no que se refere à organização do ensino médio e técnico, quais contribuições os escritos de Marx e Engels podem oferecer para o combate ao dualismo da organização escolar capitalista e para a construção da escola unitária, da educação integral/integrada?

\section{Referências}

ABENDROTH, W. A história social do movimento trabalhista europeu. Rio de Janeiro: Paz e Terra, 1977.

ANTUNES, R. Notas sobre a consciência de classe. In: ANTUNES, R.; REGO, W. D. L. (Orgs.) Lukacs. Um Galileu no século XX. São Paulo: Boitempo, 1996, p. 97-103.

BAKUNIN, M. A. A instrução integral. São Paulo: Imaginário, 2003.

CHARLOT, B. Educação e trabalho: problemáticas contemporâneas convergentes. Educação, Sociedade E Culturas, Porto, n. 22, p. 9-25, 2004.

CLOT, Y. Le travail sans l'homme. Pour une psychologie des milieux de travail et de vie. Paris: La Découverte, 1995.

COGGIOLA, O. (Org.). Marx e Engels na História. São Paulo: Xamã, 1996.

DANGEVILLE, R. Introdução. In: MARX, K.; ENGELS, F. Crítica da educação e do ensino. Lisboa: Moraes Editores, 1978.

FERRER; GUARDIA, F. La escuela moderna. Madrid: Editora Zero, 1970.

FREYMOND, J. (Org.). La Première Internationale. Genève: Droz, 1962. 2 v. 
GRAMSCI, A. Cadernos do Cárcere. V.2. Os intelectuais. O princípio educativo. Jornalismo. Ed. e trad. Carlos Nelson Coutinho. Rio de Janeiro: Civilização Brasileira, 2000.

LEFEBVRE, H. A re-produção das relações de produção. Porto: Publicações Escorpião, 1973.

LEFEBVRE, H. L'idéologie structuraliste. Paris: Èditions Anthropos, 1971.

LEFEBVRE, H. Pour connaitre Marx. Paris: Bordas, 1985.

LEFEBVRE, H. A vida cotidiana no mundo moderno. São Paulo: Ática, 1991.

LEFEBVRE, H. Une pensée devenue monde. Paris: Fayard, 1980.

LEFEBVRE. Sociologie de Marx. Paris: PUF, 1974.

LUIZETTO, F. V. As utopias anarquistas. São Paulo: Brasiliense, 1987.

LUIZETTO, F. V. O movimento anarquista em São Paulo: a experiência da Escola Moderna n. 1 (1912-1919). Educação e Sociedade, Campinas, ano VIII, n. 24, ago. 1986, p. 18-47.

LUKÁCS,G. Ontologia delser social: el trabajo.Buenos Aires:Herramienta,2004.

MACHADO, L. Politecnia, escola unitária e trabalho. São Paulo: Cortez; Autores Associados, 1989.

MANACORDA, M. Marx e a pedagogia moderna. São Paulo: Cortez; Autores Associados, 1991.

MARTINS, J. de S. As temporalidades da História na dialética de Lefebvre. In: MARTINS, J. de S. Henri Lefebure e o retorno à dialética. São Paulo: Hucitec, 1996, p. 13-24.

MARX, K. A guerra civil na França. São Paulo: Boitempo, 2011.

MARX, K. El capital. México: Siglo Veintiuno Editores, 1984.

MARX, K. Elementos fundamentales para la crítica de la Economía Política (Grundrisse) - 1857-1858. México: Siglo Veintiuno Editores, 1987.

MARX, K. Grundrisse. Manuscritos económicos de 1857-1858. Esboço da crítica da economía política. São Paulo: Boitempo, 2011.

MARX, K. La sainte famille. Paris: Editiones Sociales, 1972.

MARX, K. Le Capital. Livro 1. Paris: Editions Sociales, 1975.

MARX, K. Manuscritos economico-filosoficos de 1844. Bogotá: Editorial Pluma, 1980.

MARX, K. O capital. Livro I. São Paulo: Ciências Humanas, 1978. 
MARX, K. O capital. São Paulo: Boitempo, 2013. 3v.

MARX, K.; ENGELS, F. Manifeste du parti communiste. Paris: Nathan, 1982.

MARX, K.; ENGELS, F. A ideologia alemã. São Paulo: Boitempo, 2007.

MARX, K.; ENGELS, F. Antologia filosófica. Lisboa: Estampa, 1974.

MARX, K.; ENGELS, F. Crítica da educação e do ensino. Introdução e notas de Roger Dangeville. Lisboa: Moraes Editores, 1978

MARX, K.; ENGELS, F. Critique des programmes de Gotha et d'Erfurt. Paris: Edions Sociales, 1972.

MARX, K; ENGELS, F. Critique de l'éducation et de l'enseignement. Introduction, traduction et notes de Roger Dangeville. Paris: Maspero, 1976.

MARX; ENGELS. Obras escolhidas, v. 2. Rio de Janeiro: Vitória, 1961

MORAES, C. S. V. et al. Inventário de fontes das escolas dirigidas pelo educador anarquista João Penteado (1912-1961): dimensão pedagógica e contribuição para a história da relação trabalho e educação no Brasil. Revista Brasileira de História da Educação, v. 11, n. 1 (25), jan./abr. 2011, p. 117-141.

MUSTO, M. Trabalhadores, Uni-vos! Antologia Política da I Internacional. São Paulo: Boitempo, 2014.

NETTO, J. P.; BRAZ, M. Economia politica: uma introdução crítica. São Paulo: Cortez, 2007.

NETTO, J. P. O que é o marxismo. São Paulo: Brasiliense, 1985.

NOGUEIRA, M. A. Educação, saber, produção em Marx e Engels. São Paulo: Cortez, 1990.

OLIVEIRA, B. A.C.; MORAES, Carmen S. V. A teoria das formas em Lefebvre. In: MARTINS, J. de S. (Org.). Henri Lefebure e o retorno à dialética. São Paulo: Hucitec, 1996, p. 99-107.

PALÁCIOS, J. La Questión Escolar: críticas y alternativas. Barcelona: Editorial Laia, 1978.

PEREIRA, L. Trabalho e desenvolvimento Socialno Brasil.São Paulo: Difel,1965.

PFEFFERKORN, R. Inégalités et rapports sociaux. Rapports de classes, rapports de sexes. Paris: La Dispute, 2007.

SANTOS, L. E. dos. A educação libertária e o extraordinário. Traços de uma pedagogia (r)evolucionária. 2014. 215 f. Tese (Doutorado em Educação) - Faculdade de Educação, Universidade de São Paulo, São Paulo, 2014.

TRAGTENBERG, M. Reflexões sobre o socialismo. São Paulo: Moderna, 1986. 